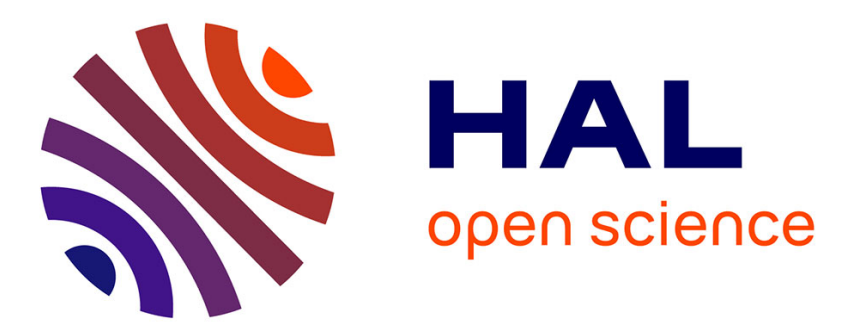

\title{
Dietary live yeast alters metabolic profiles, protein biosynthesis and thermal stress tolerance of Drosophila melanogaster
}

Hervé Colinet, David Renault

\section{- To cite this version:}

Hervé Colinet, David Renault. Dietary live yeast alters metabolic profiles, protein biosynthesis and thermal stress tolerance of Drosophila melanogaster. Comparative Biochemistry and Physiology Part A: Molecular and Integrative Physiology, 2014, 170, pp.6-14. 10.1016/j.cbpa.2014.01.004 . hal00999532

HAL Id: hal-00999532

https://hal-univ-rennes1.archives-ouvertes.fr/hal-00999532

Submitted on 3 Jun 2014

HAL is a multi-disciplinary open access archive for the deposit and dissemination of scientific research documents, whether they are published or not. The documents may come from teaching and research institutions in France or abroad, or from public or private research centers.
L'archive ouverte pluridisciplinaire $\mathbf{H A L}$, est destinée au dépôt et à la diffusion de documents scientifiques de niveau recherche, publiés ou non, émanant des établissements d'enseignement et de recherche français ou étrangers, des laboratoires publics ou privés. 


\section{Dietary live yeast alters metabolic profiles, protein biosynthesis \\ 2 and thermal stress tolerance of Drosophila melanogaster}

4 Colinet Hervé* \& Renault David

Université de Rennes 1, UMR CNRS 6553 Ecobio, 263 Avenue du Gal Leclerc, CS 74205,

$7 \quad 35042$ Rennes, France

8

9 *Address for correspondence:

Hervé Colinet, UMR CNRS 6553 Bât 14A, Université de Rennes1, 263 Avenue du Général Leclerc CS 74205, 35042 Rennes Cedex, France.

Tel: +33 (0)223233667

Fax: +33(0)223235026

Email: herve.colinet@univ-rennes1.fr

Running headline: nutrition affects cold tolerance

Keywords: fruit fly, nutrition, live yeast, metabolic fingerprinting, cold stress 


\section{Abstract}

The impact of nutritional factors on insect's life-history traits such as reproduction and lifespan has been excessively examined; however, nutritional determinant of insect's thermal tolerance has not received a lot of attention. Dietary live yeast represents a prominent source of proteins and amino acids for laboratory-reared drosophilids. In this study, Drosophila melanogaster adults were fed on diets supplemented or not with live yeast. We hypothesized that manipulating nutritional conditions through live yeast supplementation would translate into altered physiology and stress tolerance. We verified how live yeast supplementation affected body mass characteristics, total lipids and proteins, metabolic profiles and cold tolerance (acute and chronic stress). Females fed with live yeast had increased body mass and contained more lipids and proteins. Using GC/MS profiling, we found distinct metabolic fingerprints according to nutritional conditions. Metabolite pathway enrichment analysis corroborated that live yeast supplementation was associated with amino acid and protein biosyntheses. The cold assays revealed that the presence of dietary live yeast greatly promoted cold tolerance. Hence, this study conclusively demonstrates a significant interaction between nutritional conditions and thermal tolerance.

(1)

2




\section{Introduction}

A number of studies have examined how nutrition affects various traits in insects, with special emphasis on the effects of dietary intake on reproduction and longevity (Le Bourg and Medioni, 1991; Chippindale et al., 1993; Leroi et al., 1994; Anagnostou et al., 2010). More specifically, the trade-off between reproduction and lifespan resulting from the qualitative and quantitative manipulations of diet has been studied extensively (Carey et al., 2008; Ellers et al., 2011; Moore and Attisano, 2011). Drosophila melanogaster is a very popular model used in the dietary restriction (DR) literature of gerontology because of its relatively short generation time and ease of handling for demographic analysis (Partridge et al., 2005). The composition of Drosophila sp. food recipes often varies among laboratories and medium types, but the standard ingredients usually include water, agar, sugar, killed yeast, and fungicides. In addition, the medium can be supplemented with live yeast. Often adding live yeast on the surface of the diet strongly stimulates females to lay eggs (Markow and O'Grady, 2006; Stocker and Gallant, 2008). Dietary yeast is a major source of nutrition for the adults and larvae of most saprophagous Drosophila (Diptera: Drosophilidae) (Begon, 1982). It provides essential nutrients for the developmental and reproductive processes such as amino acids, sterols, vitamins, and fatty acids (Davis, 1975; Anagnostou et al. 2010). As a result, the concentration of yeast in the artificial diet is the primary determinant of egg production in $D$. melanogaster (Sang and King, 1961; Skorupa et al., 2008), and the formation of yolk proteins can thus be strongly curtailed by depriving flies of nutritional proteins or essential amino acid present in yeasts (Sang and King 1961; Bownes et al., 1988; Chippindale et al., 1993). Hence, the incorporation of live yeast in mediums highly stimulates vitellogenesis because it provides essential nutrients that are not necessarily present in large amounts in the usual adult food (Sang and King, 1961; Simmons and Bradley, 1997).

Owing to the major importance of the nutritional status on physiological and biochemical processes of insects, any alteration of nutritional regime is likely to affect all aspects of their life, including not only reproduction but also stress tolerance (such as thermal tolerance) (Hallman and Denlinger, 1998; Chown and Nicolson, 2004; Nyamukondiwa and Terblanche, 2009; Andersen et al., 2010; Colinet and Boivin, 2011; Sisodia and Singh, 2012). Yet, a limited number of studies have considered the impact of nutritional resources on environmental stress tolerance, and more particularly on thermal tolerance (Andersen et al., 2010). In this particular respect, no clear-cut response has been observed as nutritional effects on thermal tolerance seem to be rather complex and involve many interacting factors. 
Carbohydrate-rich diets tend to increase drosophilids' cold tolerance compared to protein-rich diets, and the opposite effect is observed on measures of heat resistance (Andersen et al., 2010; Sisodia and Singh, 2012). However, when supplemented at high levels, dietary sugars induce a severe nutritional imbalance and a pathological state in D. melanogaster (Wang and Clark, 1995; Skorupa et al., 2008; Musselman et al., 2011; Colinet et al., 2013a) and these high sugar doses negatively affect cold tolerance (Colinet et al., 2013a). Quantitative manipulation of food supply via dietary restriction (i.e. dilution.) has no detectable effect on cold tolerance (chill-coma recovery, CCR) of young flies and only marginally reduces cold tolerance later in adult life (Burger et al., 2007). Removing (or adding) live yeast from $D$. melanogaster food also impacts on thermal traits in a rather complex manner. Le Rohellec and Le Bourg (2009) found that removing live yeast only weakly decreased cold survival of females subjected to a $16 \mathrm{~h}$ coldshock $\left(0{ }^{\circ} \mathrm{C}\right)$, but only when these were mated. In another study, absence of live yeast in food killed nearly $100 \%$ of flies (males and females) subjected to the same cold treatment, whereas access to live yeast resulted in medium to high survival rate depending on age (Le Bourg, 2010). Tolerance to heat $\left(37^{\circ} \mathrm{C}\right)$ was either unaffected (Le Bourg, 2010) or improved by removal of live yeast (but in young females only) (Le Rohellec and Le Bourg, 2009). From the above examples, it seems clear that nutritional status can be a significant component of thermal tolerance of insects, affecting both heat- and cold-related traits. It also appears that nutritional effects on thermal tolerance depend on several interacting factors including gender, mating status, and age. Although the physiological and biochemical basis of thermal responses is becoming clearer through metabolic and physiological studies (Overgaard et al., 2007; Doucet et al., 2009; Colinet et al., 2012a; Kostál et al., 2012; Storey and Storey, 2012; Teets and Denlinger 2013), there remains limited information on the physiology of nutrition-mediated variation in thermal tolerance. A way in which insects deal with nutrient variations is through altered physiology, namely by affecting developmental and metabolic processes (Markow et al., 1999). Therefore, it can be assumed that manipulating the source of essential nutrients found in live yeast, such as amino acids and proteins, could alter the physiology and also the general stress tolerance.

In the present study, we completed a comprehensive assessment of the impact of dietary live yeast supplementation on body mass characteristics, proteins, metabolic profiles and basal cold tolerance (to acute and chronic exposures) in D. melanogaster females. We hypothesized that the absence of the source of proteins (i.e. live yeast) from adult food would be associated with deep physiological alterations; therefore, we expected contrasted metabolic 
profiles (i.e. metabotype) between yeast-deprived and yeast-fed females. Because live yeast is a rich source of proteins and amino acids, we hypothesized that pathways related to protein biosynthesis would be particularly targeted by dietary live yeast supplementation. In addition, we expected body mass parameters to be strongly curtailed by depriving females of live yeast. Finally, we hypothesized that the nutritional and the metabolic variations caused by manipulating dietary live yeast will translate into altered thermal stress tolerance.

\section{Materials and methods}

\subsection{Fly culture and diets}

We conducted the experiments on a mass-bred $D$. melanogaster line derived from the mix of two wild populations collected in October 2010 and September 2011 at Plancoët (Brittany, France). Prior to the experiment, flies were maintained in laboratory in $200 \mathrm{~mL}$ bottles at $25 \pm 1{ }^{\circ} \mathrm{C}(16 \mathrm{~L}: 8 \mathrm{D})$ on standard fly medium consisting of deactivated brewer yeast (80 g/L) (MP Biochemicals, Illkirch, France), sucrose (50 g/L), agar (15 g/L), kalmus (9 g/L) and Nipagin ${ }^{\circledR}(8 \mathrm{~mL} / \mathrm{L})$ as described previously (Colinet et al., 2013a). To generate flies for the experiments, groups of 15 mated females were allowed to lay eggs during a restricted period of $6 \mathrm{~h}$ in bottles $(200 \mathrm{~mL})$ containing $25 \mathrm{~mL}$ of standard fly medium. This controlled procedure allowed larvae to develop under uncrowded conditions at $25 \pm 1{ }^{\circ} \mathrm{C}$ (16L:8D). At emergence, adult flies were allowed to age for six days on different diets and controls. The diets were changed every day for six consecutive days. Two different experiments were used to assess the effect of adult dietary live yeast supplementation (see Fig. 1 for experimental design).

- Experiment 1 (conducted in 2012): minimal control diet versus live yeastsupplemented diet. Sugar and agar [SA] versus sugar, agar, live yeast [SAY(+)].

- Experiment 2 (conducted in 2013): standard control diet versus live yeastsupplemented diet. Sugar, agar, killed yeast [SAY(-)] versus sugar, agar, killed yeast and live yeast $[\mathbf{S A Y}( \pm)]$.

In the first experiment, emerging flies did not have any nutrient supply except from sugar. It is thus conceivable that these flies could suffer from malnutrition. Therefore, a second 
experiment was designed with a standard diet as control that contains protein supply [SAY(-)] rather than a minimal diet $[\mathrm{SA}]$, in order to assess the effect of dietary live yeast supplementation without any putative malnutrition. In both experiments, the amounts of sugar, agar and killed yeast when supplied were $50 \mathrm{~g} / \mathrm{L}, 15 \mathrm{~g} / \mathrm{L}$ and $80 \mathrm{~g} / \mathrm{L}$ respectively. When supplemented, the live yeast was provided with ad libitum paste placed on the surface of the food [i.e. for SAY(+) and SAY( \pm$)$ ]. We used synchronized six day-old adults for all assays to avoid the uncontrolled variation of stress tolerance during the first days of age (Colinet et al., 2013b). Adults were sexed visually (with an aspirator) without $\mathrm{CO}_{2}$ to avoid any confusing metabolic effects due to anaesthesia (Colinet and Renault, 2012), and only females were kept. Six day-old females from each nutritional group were either directly used for the cold assays or snap-frozen in liquid nitrogen and stored at $-80{ }^{\circ} \mathrm{C}$ for the other assays.

\subsection{Body mass and protein levels}

We assessed total protein content using the Bradford procedure (Bradford, 1976). Twelve biological replicates, each consisting of a pool of three females, were used for each experimental condition. Each sample was vacuum-dried (GENEVAC, model DNA-23050B00) set at $30{ }^{\circ} \mathrm{C}$ for $24 \mathrm{~h}$ and then weighed (dry mass, Mettler Toledo UMX2, accurate to 1 $\mu \mathrm{g})$ before proteins were extracted in a phosphate buffer $\left(100 \mathrm{mM} \mathrm{KH}_{2} \mathrm{PO}_{4}, 1 \mathrm{mM}\right.$ DTT and 1 mM EDTA, pH 7.4, Foray et al., 2012) and homogenized using bead-beating at $25 \mathrm{~Hz}$ for 1.5 min. The concentration of total proteins was then measured in the whole body extracts using Bio-Rad Protein Assay (catalog number 500-0006) following manufacturer's instructions.

For each nutritional treatment, 15 females were subjected to individual fresh mass (FM) measurements (Mettler Toledo UMX2, accurate to $1 \mu \mathrm{g}$ ). Then, individual females were dried at $60{ }^{\circ} \mathrm{C}$ for two days, and reweighed to measure dry mass (DM). Water mass (WM) was determined by subtracting DM from FM. Water content (WC) represents the ratio WM/FM. Lean dry mass (LDM) was measured by extracting total lipids in a chloroform/methanol solution (Folch reagent 2:1, v:v) for one week under continuous agitation. The samples were then dried at $60{ }^{\circ} \mathrm{C}$ to eliminate residues of the extracting solution before measurement of LDM. Body lipid mass (LM), corresponding to DM-LDM, was calculated (see Colinet et al., 2006). Folch reagent may extract a small fraction of other 
compounds than lipids, but measurements obtained with this method are still considered as a good index of lipid content for comparative studies (Williams et al., 2011).

\subsection{Cold tolerance assays}

Different metrics were used to assess cold tolerance. First, recovery time following a non-lethal chronic cold stress was measured (i.e. chill-coma recovery, CCR). Fifty females were exposed to $0{ }^{\circ} \mathrm{C}$ for various durations: 8,10 and $12 \mathrm{~h}$ for the flies of the experiment 1 [i.e. SA vs. SAY(+)], and 10 and $12 \mathrm{~h}$ for the flies of the experiment 2 [i.e. SAY(-) vs. $\mathrm{SAY}( \pm)]$. Cold-exposed flies were then allowed to recover at $25 \pm 1{ }^{\circ} \mathrm{C}(16 \mathrm{~L}: 8 \mathrm{D})$ and recovery times were individually recorded; flies were considered recovered when they stood up. A cold incubator (Model MIR-153, SANYO Electric Co. Ltd, Japan) was used for the assays. After scoring the recovery times, the same females were returned to $25 \pm 1{ }^{\circ} \mathrm{C}$ (16L:8D) on their respective diet and the mortality was scored after $24 \mathrm{~h}$ (i.e. latent damage assessment).

Second, tolerance to acute cold stress was measured. A total of 100 females (5 replicates, 20 females per replicate) were placed in $42 \mathrm{~mL}$ glass vials immersed in a glycol solution cooled to $-3.5{ }^{\circ} \mathrm{C}$ for different durations: 90,120 and $135 \mathrm{~min}$ for the flies of the experiment 1 [i.e. SA vs. SAY(+)], and 90 and $120 \mathrm{~min}$ for the flies of the experiment 2 [i.e. SAY(-) vs. $\mathrm{SAY}( \pm)]$. After the acute cold stress, the flies were returned to $25^{\circ} \mathrm{C}$ on their respective diet, and the mortality was scored after $24 \mathrm{~h}$. Most mortality in D. melanogaster adults happens within $24 \mathrm{~h}$ after the cold stress (Rako and Hoffmann, 2006), and we therefore did not consider a longer period.

\subsection{Metabolic fingerprinting}

The metabolic effect of dietary live yeast supplementation was assessed by comparing the metabotypes of SA vs. SAY(+) (experiment 1) and SAY(-) vs. SAY( \pm ) (i.e. experiment 2). To ensure that the differences observed were not only related to presence/absence of live yeast in the gut content, we included an additional treatment where flies were starved before sampling. In this experiment 3 (conducted in 2013), the same flies as in the experiment 2 were starved for $8 \mathrm{~h}$ on agar before their metabolic profiles were compared. Hence, we compared the 
following conditions: sugar, agar, killed yeast, plus 8h starvation (St-SAY-) versus sugar, agar, killed yeast and live yeast, plus 8h starvation (St-SAY \pm ) (see Fig. 1).

For each nutritional group, six biological replicates, each consisting of a pool of 15 females, were used for metabolic fingerprinting. Each sample was weighed (Mettler Toledo UMX2, accurate to $1 \mu \mathrm{g}$ ) before metabolite extractions. Sample preparation and derivatization were performed as previously described (Colinet et al., 2012b), with minor modifications. Briefly, after homogenisation in methanol-chloroform solution $(2: 1, \mathrm{v}: \mathrm{v})$ and phase separation with $400 \mu \mathrm{L}$ of ultrapure water, an $120 \mu \mathrm{L}$ aliquot of the upper phase, which contained polar metabolites, was vacuum-dried. The dry residue was resuspended in $30 \mu \mathrm{L}$ of $20 \mathrm{mg} \mathrm{mL} \mathrm{m}^{-1}$ methoxyamine hydrochloride in pyridine before incubation under automatic orbital shaking at $40{ }^{\circ} \mathrm{C}$ for $60 \mathrm{~min}$. Then, $30 \mu \mathrm{L}$ of MSTFA were added and the derivatization was conducted at $40{ }^{\circ} \mathrm{C}$ for 60 min under agitation (see Colinet et al., 2012b). A CTC CombiPal autosampler (GERSTEL GmbH and Co.KG, Mülheim an der Ruhr, Germany) was used, ensuring standardized sample preparation and timing. Metabolites were separated, identified and quantified using a GC/MS platform consisting of a Trace GC Ultra chromatograph and a Trace DSQII quadrupole mass spectrometer (Thermo Fischer Scientific Inc, Waltham, MA, USA). The oven temperature ranged from 70 to $170{ }^{\circ} \mathrm{C}$ at $5{ }^{\circ} \mathrm{C} \mathrm{min}^{-1}$, from 170 to $280{ }^{\circ} \mathrm{C}$ at 7 ${ }^{\circ} \mathrm{C} \mathrm{min}{ }^{-1}$, from 280 to $320{ }^{\circ} \mathrm{C}$ at $15^{\circ} \mathrm{C} \mathrm{min}^{-1}$, and then, the oven remained at $320{ }^{\circ} \mathrm{C}$ for $4 \mathrm{~min}$. We completely randomized the injection order of the samples. All samples were run under the SIM mode rather than the full-scan mode. We therefore only screened for the 63 pure reference compounds included in our custom spectral database. Calibration curves for 60 pure reference compounds at 5, 10, 20, 50, 100, 200, 500, 750, 1000, 1500 and $2000 \mu \mathrm{M}$ concentrations were run concurrently. Chromatograms were deconvoluted using XCalibur 2.0.7, and metabolite levels were quantified using the quadratic calibration curve for each reference compound and concentration. Arabinose was used as the internal standard (see Colinet et al., 2012b). Among the 63 metabolites included in our spectral library, 37, 34 and 34 compounds were detected in the samples from experiment 1, 2 and 3 respectively (see Table 1 for compounds' list and abbreviations).

\subsection{Statistics}

Since allometric relationship may exist between the body mass parameters and size, we first determined if the variables were linearly related to LDM (with least-squares regressions) 
(Packard and Boardman, 1999). Analysis of covariance (ANCOVA) was then used if linear

242 relationships was established, using LDM as co-variable, whereas analysis of variance

243 (ANOVA1) was used with nutritional treatment as factor when the allometric relationship was not found. The same approach was used for analysing the protein content but with DM as covariable. Comprehensive details on regression statistics and individual plots are shown in supplementary file S1. For cold tolerance, Chi-square contingency tests were used to compare mortality rates between nutritional groups (with Yates' correction to prevent overestimation of statistical significance). For CCR, the data were used to generate temporal recovery curves which were compared with Mantel-Cox (Log rank) test. This non parametric method tests the null hypothesis that there is no difference between the populations in the probability of an event at any time point (i.e. a curve comparison test). Analyses were performed using Prism v. 5.01 (GraphPad Software, Inc., San Diego, CA, USA, 2007) or the statistical software 'R 2.13.0' (R Development Core Team, 2008). For metabolic data, a principal component analysis (PCA) was performed on the whole dataset to detect the compounds contributing the most to the separation between the nutritional groups. The inertia calculated in the PCA represents the part of the total variance that is due to the difference between modalities. Scaled data (i.e. mean-centered and divided by $\sqrt{ } S D$ ) were used in the multivariate analyses to prevent the effects of the metabolite concentration means and ranges of variability on the correlations with the principal components (PCs). This analysis was performed using the 'ade4' library in the statistical software 'R 2.13.0'. In addition, to look for evidence of enriched metabolic pathways in response to dietary live yeast supplementation, metabolite pathway enrichment analysis (MPEA) was conducted using MetPA online package, with $D$. melanogaster specific library (Xia and Wishart, 2010), as previously described (Colinet et al., 2013a).

\section{Results}

\subsection{Body mass and protein levels}

The Figure 2 summarizes the variations in mass parameters according to nutritional treatments. The DM corresponds to the sum of LM and LDM, and FM corresponds to the sum of LM, LDM and WM (Fig. 2). Females fed with live yeast [SAY(+) and SAY( \pm )] were heavier in terms of FM and DM than their counterparts fed without live yeast. Since FM and 
DM were linearly related to LDM $(P<0.05$; see supplementary file $S 1)$, we used ANCOVA to assess the effect of nutritional treatment with LDM as co-variable. The effect of the treatment remained significant even when the allometric effect of size was removed (FM: $F=$ 30.69, $d f=3, P<0.001$; DM: $F=8.27, d f=3, P<0.001 ; n=15)$. Multiple comparisons revealed that $\mathrm{SA}<\mathrm{SAY}(-)<\mathrm{SAY}(+)=\mathrm{SAY}( \pm)$ for $\mathrm{FM}$, and $\mathrm{SA}<\mathrm{SAY}(-)=\mathrm{SAY}(+)=$ $\mathrm{SAY}( \pm)$ for DM. The WM was also correlated to $\operatorname{LDM}(P<0.05$; see supplementary file $\mathrm{S} 1)$. The ANCOVA revealed a significant effect of the treatment $(F=29.94, d f=3, P<0.001 ; n=$ 15). Multiple comparisons revealed that $\mathrm{SA}<\mathrm{SAY}(-)<\mathrm{SAY}(+)=\mathrm{SAY}( \pm)$ for WM. Contrary to WM, the WC was unrelated to $\mathrm{LDM}(P>0.05$; see supplementary file $\mathrm{S} 1)$ and the ANOVA did not detect variation according to the diet treatment $(F=0.197, d f=3, P=1.61$; $n=15)$. The LM was unrelated to LDM ( $P>0.05$; see supplementary file S1), and ANOVA detected a significant effect of nutritional treatment, with a lower total lipid content for the treatment SA $(F=10.4, d f=3, P<0.001 ; n=15)$. The LDM varied according to nutritional treatment $(F=76.14, d f=3, P<0.001 ; n=15)$, with the following rank order: SA $<$ SAY(-) $<\mathrm{SAY}(+)<\mathrm{SAY}( \pm)$. Finally, the total protein content was not related to DM $(P>0.05$; see supplementary file S1), and ANOVA revealed a significant effect of nutritional treatment $(F=$ 155.3, $d f=3, P<0.001 ; n=12)$, with higher protein contents in females fed with live yeast [i.e. $\mathrm{SA}<\mathrm{SAY}(-)<\mathrm{SAY}(+)<\mathrm{SAY}( \pm)]$.

\subsection{Cold tolerance}

Concerning cold tolerance, we found that CCR significantly varied between the two nutritional groups of the experiment 1, with females fed on SAY $(+)$ diet recovering faster than females fed on SA diet (Fig. 3). This difference manifested for all the durations of cold stress that were tested in the experiment $1\left(8 \mathrm{~h}: C h i^{2}=19.17, d f=1, P<0.001 ; 10 \mathrm{~h}: C h i^{2}=\right.$ 16.29, $\left.d f=1, P<0.001 ; 12 \mathrm{~h}: C h i^{2}=14.65, d f=1, P<0.001 ; n=50\right)$. Survival after chronic cold stress was also affected by nutritional regime. For all the durations of cold stress at $0{ }^{\circ} \mathrm{C}$ (8, 10 and $12 \mathrm{~h})$, the post-stress mortality was significantly lower when females fed on SAY(+) diet compared to SA diet $\left(8 \mathrm{~h}: C h i^{2}=21.23, d f=1, P<0.001 ; 10 \mathrm{~h}: C h i^{2}=19.10, d f\right.$ $\left.=1, P<0.001 ; 12 \mathrm{~h}: C h i^{2}=21.23, d f=1, P<0.001 ; n=50\right)$ (Fig. 3). Finally, the acute cold tolerance also varied with the nutritional regimes of the experiment 1 (Fig. 3). For all the durations of cold stress at $-3.5{ }^{\circ} \mathrm{C}(90,120$ and $135 \mathrm{~h})$, the post-stress mortality was significantly lower when females fed on $\mathrm{SAY}(+)$ diet compared to SA diet $\left(90 \mathrm{~min}\right.$ : $\mathrm{Chi}^{2}$ 
$=39.61, d f=1, P<0.001 ; 120 \mathrm{~min}: C h i^{2}=35.57, d f=1, P<0.001 ; 135 \mathrm{~min}: C h i^{2}=17.56, d f=$ $1, P<0.001 ; n=100)$.

The cold tolerance of the flies from the experiment 2 was also affected by the nutritional treatments; however, this was not manifested on CCR. Females feeding on SAY(-) and SAY $( \pm)$ recovered from chronic cold stress with similar temporal dynamics $\left(10 \mathrm{~h}: C h i^{2}=\right.$ 2.55, $d f=1, P=0.10 ; 12$ h: $C h i^{2}=1.01, d f=1, P=0.31 ; n=50$ ) (Fig. 4). On the other hand, the survival after the chronic cold stress was affected by the nutritional regimes. For both durations of chronic cold stress (10 and $12 \mathrm{~h}$ ), the post-stress mortality was significantly lower when females fed on SAY $( \pm)$ diet compared to SAY(-) diet $\left(10 \mathrm{~h}: C h i^{2}=5.02, d f=1, P=\right.$ 0.025; 12 h: $C h i^{2}=16.94, d f=1, P<0.001 ; n=50$ ) (Fig. 4). Finally, the acute cold tolerance also varied with the nutritional regimes of the experiment 2 . For both durations of acute cold stress at $-3.5{ }^{\circ} \mathrm{C}(90$ and $120 \mathrm{~h})$, the post-stress mortality was significantly lower when females fed on SAY( \pm ) diet compared to SAY(-) diet (90 min: $C h i^{2}=69.01, d f=1, P<0.001$; 120 min: $C h i^{2}=66.66, d f=1, P<0.001 ; n=100$ ) (Fig. 4).

\subsection{Metabolic fingerprinting}

The metabolic profiles of flies from experiment 1 showed that a number of metabolites had their concentrations affected by dietary live yeast, which resulted in contrasted metabotypes between the two nutritional groups (Fig. 5). A clear-cut separation was observed along the first principal component (PC1) of the PCA, which accounted for $43.9 \%$ of the total inertia (Fig. 5). GDL, Fru, Glc, Tre and sorbitol were the molecules the most positively correlated to PC1 (i.e. accumulated in SA flies), whereas on the opposite side, the amino acids Val, Ile, Leu, Thr, Gly, Phe and Glu were the molecules the most negatively correlated to PC1 (i.e. accumulated in SAY(+) flies) (Fig. 5). The other principal components accounted for $28.4 \%$ (PC2) and $11.3 \%$ (PC3) of the total inertia and mainly represented within-treatment variations. MPEA based on the metabolites that were positively correlated to PC1 revealed three enriched metabolic pathways (Holm adjust $P<0.05$ ), and all were directly involved in carbohydrate metabolism. MPEA based on all the metabolites that were negatively correlated to PC1 revealed three enriched metabolic pathways; all were directly involved in amino acids and protein biosynthesis (see Dataset S1 for detailed concentrations and fold changes). 
Similar results were obtained with the flies from experiment 2. A clear-cut separation was observed along the PC1 of the PCA, which accounted for $47.1 \%$ of the total inertia (Fig. 6). Fru, Tre, xylitol, Glc and GDL were the most positively correlated to PC1 (i.e. accumulated in SAY(-) flies), whereas on the opposite side, Glu, inositol, Leu, Phe and Val were the most negatively correlated metabolites to PC1 (i.e. accumulated in SAY( \pm ) flies) (Fig. 6). The other principal components accounted for 31.6\% (PC2) and 6.4\% (PC3) of the total inertia and mainly represented within-treatment variations. MPEA also revealed that that carbohydrate metabolism was enriched in the SAY(-) flies, while amino acids and protein biosynthesis were enriched in the SAY $( \pm)$ flies (see Dataset S2 for detailed concentrations and fold changes).

Finally, the addition of a starvation period to empty the gut content of the flies before assessing the flies (i.e. experiment 3) resulted in a similar metabolic response. Again, a clearcut separation was observed along the PC1, which accounted for $57.3 \%$ of the total inertia (Fig. 7). Xylitol, Man, Ala, Fru, Tre and Glc were the most positively correlated metabolites to PC1 (i.e. accumulated in St-SAY(-) flies), whereas Glu, Thr, Ile, Phe, inositol and Leu were the most negatively correlated to PC1 (i.e. accumulated in $\mathrm{SAY}( \pm)$ flies) (Fig. 7). The other principal components accounted for $21.2 \%$ (PC2) and $7.15 \%$ (PC3) of the total inertia. MPEA also revealed that that carbohydrate metabolism was enriched in the St-SAY(-) flies, while amino acids and protein biosynthesis were enriched in the St-SAY $( \pm)$ flies (see Dataset S3 for detailed concentrations and fold changes).

\section{Discussion}

Dietary yeast is a major source of nutrition for the adults and larvae of most saprophagous Drosophila sp. (Diptera: Drosophilidae) (Begon, 1982), and as a consequence, yeast is typically incorporated into artificial diets (Markow and O'Grady, 2006; Stocker and Gallant, 2008). Dietary yeast provides essential nutrients such as amino acids, sterols, vitamins, and fatty acids (Davis, 1975; Anagnostou et al., 2010). We assumed that removing or adding live yeast from adult food at eclosion would be associated with physiological remodelling that would subsequently affect fitness-related traits such as body size and stress tolerance. In the present study, we completed a comprehensive assessment of the impact of 
dietary live yeast supplementation on body mass characteristics, stored proteins, metabolic profiles and basal cold tolerance (to acute and chronic exposures) in D. melanogaster females.

We expected body mass parameters to be affected by dietary live yeast supplementation. Indeed, the body mass of the flies is known to reflect protein level in food, with high levels of dietary yeast leading to heavier flies (Skorupa et al., 2008). We have conclusively shown that body mass parameters (FM, DM, WM, LM and LDM) increased when females were fed with live yeast, which is consistent with previous studies (Simmons and Bradley, 1997; Le Rohellec and Le Bourg, 2009). For all the considered mass parameters, the SA flies had significantly smaller values than the SAY(-) flies which shows that SA flies disproportionally suffered from the complete lack of dietary protein and suggests a malnutrition in this group. Concerning the fat (i.e. LM), we found that the SA flies had lower stored fat than the live yeast-fed flies [i.e. SAY $(+), \operatorname{SAY}( \pm)]$, but this reduction was not observed in SAY(-) flies. Hence, the reduction of fat was not related to the suppression of live yeast per se, but to the complete suppression of proteins supply from the diet (i.e. SA). It was previously reported that the increase in body mass with dietary live yeast is almost exclusively due to increased ovary size (Simmons and Bradley, 1997), and ovaries comprise approximately $15 \%$ of the body lipids of insects (Lease and Wolf, 2011). The lower LM of the flies on SA diet is not surprising as these flies had small ovaries and hardly produced eggs (data not shown). The LDM was different among all treatments and a corresponding pattern was observed for the protein content. This suggests that feeding on a diet that contains killed yeast $[\mathrm{SAY}(-)]$ provides proteins to the flies, but feeding on a diet that also contains live yeast provides additional amounts of proteins. Storage of proteins is largely independent of dietary carbohydrates but is almost exclusively determined by the presence and concentration of yeast in the medium (Skorupa et al., 2008). Our data corroborate this idea.

A way in which insects deal with nutrient variations is through altered physiology, namely by affecting developmental and metabolic processes (Markow et al., 1999). Therefore, we assumed that manipulating the adult food (via live yeast supplementation) would be associated with physiological changes that would translate into contrasted metabolic profiles between nutritional groups. We have conclusively shown that a number of metabolites had their concentrations affected by the nutritional treatments, which resulted in contrasted metabotypes between live yeast-supplemented flies $[\mathrm{SAY}(+)$ and $\mathrm{SAY}( \pm)]$ and the control flies. Whatever the control used [SA or SAY(-) or St-SAY(-)], a similar response was repeatedly observed : sugars (Fru, Glc, and Tre) exhibited elevated amounts in the control 
whereas amino acid amounts (Val, Ile, Leu, Thr, Gly, Phe and Glu) were more abundant in the live yeast-supplemented groups. The fact that the relative abundance of sugars was higher in SA metabotype is not surprising, as these flies were fed on a minimal diet with no access to any source of proteins from adult eclosion. For the flies fed on SAY(-) and St-SAY(-) diets, the increased levels of sugars likely translates that these diets were proportionally richer in sugar than the corresponding live yeast-supplemented diets. We also found that GDL, sorbitol and xylitol contributed to the control metabotypes. GDL is a metabolite (a lactone) resulting from the degradation of Glc through the pentose phosphate pathway (Garrett and Grisham, 1999). Polyols such as sorbitol are derived from hexose monophosphates and can be produced from both Glc and Fru (Storey, 1983; Wolfe et al., 1998). The higher relative abundance of these sugar-related compounds is thus congruent with the nutritional regime of the flies. Moreover, MPEA revealed several enriched metabolic pathways associated with the control metabotypes [SA or SAY(-) or St-SAY(-)], and all of them were directly involved in the carbohydrate metabolism. This further confirmed the relative higher impact of sugars in shaping the metabotype of these nutritional groups. Concerning the live yeast-fed flies, we found a higher relative abundance of amino acids (e.g. Val, Ile, Leu, Thr, Gly, Phe and Glu) associated with these nutritional groups. This response was observed whatever the treatment used $[\mathrm{SAY}(+)$ or SAY $( \pm)$, or St-SAY $( \pm)]$. This is congruent with the nutritional regime of these flies. Live yeast is known to provide essential nutrients such as proteins and amino acids (Davis 1975; Anagnostou et al. 2010). This most likely explains why MPEA revealed several enriched metabolic pathways related to amino acids and protein biosynthesis in these nutritional groups. This biological interpretation also coincides with the larger body protein content detected in these nutritional groups. The differences observed in the metabolic profiles between the live yeast-supplemented and the control groups may also be partly due to different food intake and thus incorporation of nutrients. Indeed, food intake increases with concentration of dietary yeast in D. melanogaster (Min and Tara, 2006). The fact that metabolic patterns were consistent among experiments suggest that (i) live yeast promotes amino acids biosynthesis even when the flies are already fed with killed yeast, and (ii) that differences observed were not related to presence/absence of live yeast in the gut content.

Many insect species feed on yeasts and the effects of this nutritional resource on the growth, fecundity and survival has been demonstrated in a wide range of species (e.g. Starmer and Fogleman, 1986; Ganter 2006; Anagnostou et al. 2010). In spite of this, there is limited information on nutrition-mediated variations in stress tolerance in insects, and more 
particularly regarding thermal tolerance (Andersen et al., 2010). Here, we report convincing evidence that supplementing adult flies with sources of dietary proteins and amino acids (live yeast) promoted their subsequent cold tolerance. This positive effect of live yeast was repeatedly found in almost all of the metrics used to assess their cold tolerance (acute and chronic tolerance), and for all the stress intensities applied in the first experiment. In the second experiment, CCR was not affected by live yeast supplementation, but all the other assays (post-stress survival) supported a positive effect of live yeast on cold tolerance. Previous works reported an effect of dietary yeast on Drosophila cold tolerance, but the effects ranged from weak to very intense, and were thus difficult to interpret. For instance, Le Rohellec and Le Bourg (2009) found that removing live yeast weakly decreased cold survival of females subjected to a $16 \mathrm{~h}$ cold-shock $\left(0{ }^{\circ} \mathrm{C}\right)$, but only when these were mated. In another study, the absence of live yeast in food killed nearly all flies (males and females) subjected to the same cold treatment, whereas access to dietary yeast resulted in medium to high survival rates, depending on the age of the specimens (Le Bourg, 2010). These incongruities likely arise from the fact that nutrition-related variation in thermal tolerance involves interacting factors such as age, mating and gender. It remains unclear why in our study the CCR was affected by the nutritional treatment in the experiment 1 but not in the experiment 2. Longer temporal recovery dynamics of the SA flies (experiment 1) could result from the lack of essential nutrients necessary for an optimal functioning of the wholesystem physiology, or from an excessive amount of consumed sugars (as sugar was the sole source of food in this specific group). With regard to sugars, it appears that carbohydrateenriched diets tend to increase Drosophila cold tolerance (Andersen et al., 2010; Sisoda and Singh, 2012). However, when provided at too high levels, dietary sugars induce a severe nutritional imbalance and a pathological state in D. melanogaster (Wang and Clark, 1995; Skorupa et al., 2008; Musselman et al., 2011; Colinet et al., 2013a), which in turn negatively affects cold tolerance including CCR (Colinet et al., 2013a). In spite of this, our data and earlier observations (Le Rohellec and Le Bourg, 2009; Le Bourg, 2010) all converge towards the same conclusion that cold tolerance of the females of D. melanogaster is generally promoted by dietary live yeast. Females fed with live yeast had increased body mass and contained more lipids and proteins, and MPEA corroborated that live yeast supplementation was associated with amino acids and protein biosyntheses. Interestingly, it was previously found in D. melanogaster that the level of glycogen, triglycerides, and total proteins was higher in cold-selected than in control lines (Chen and Walker, 1994). The same authors also noted that these levels quickly decreased $24 \mathrm{~h}$ after a cold stress and 
suggested that higher storage of energy reserves entails increased cold tolerance of coldselected lines. Thus, the higher energy reserves of the live yeast-supplemented flies may explain why cold survival (assessed after $24 \mathrm{~h}$ ) was higher in this nutritional group.

Stressful conditions are known to critically increase energy expenditure because the repairing mechanisms require excess of energy (Parsons, 1991). We suggest that in nutrientunbalanced conditions (e.g. SA), individuals might disproportionately suffer from stressful conditions because the metabolically available energy is already constrained. The ability to synthesize essential stress-related proteins, due to dietary depletion of amino acids and protein building blocks could be an alternate explanation for the reduced cold tolerance. Hence, dietary balance is likely to be a key point of environmental stress physiology. Stress tolerance is probably compromised under conditions of excessive nutritional imbalance, as for life-history traits (Skorupa et al., 2008). In the natural environment, larvae may occasionally face nutritional stress and this might further affect the stress tolerance of the adults (carry-over effect), however, this question has not been examined. This study conclusively demonstrates an interaction between dietary live yeast and thermal stress tolerance of $D$. melanogaster females. Whether dietary live yeast positively affects the tolerance to other stressors remains to be further examined. Moreover, the mechanistic link between thermal tolerance and dietary live yeast remains an open question. Understanding the link between thermal stress tolerance and nutrient quality represents an important step in physiological ecology that may further add to our understanding of thermal biology of ectotherms.

\section{Acknowledgments}

This study was supported by Observatoire des Sciences Universelles Rennais (OSUR). We are grateful to Raphael Bical for technical help and to anonymous referees for helping improving the manuscript 


\section{Reference}

Anagnostou, C., Dorsch, M. and Rohlfs, M., 2010. Influence of dietary yeasts on Drosophila melanogaster life-history traits. Entomol. Exp. Appl. 136, 1-11.

Andersen, L.H., Kristensen, T.N., Loeschcke, V., Toft, S., Mayntz, D., 2010. Protein and carbohydrate composition of larval food affects tolerance to thermal stress and desiccation in adult Drosophila melanogaster. J. Insect Physiol. 56, 336-340.

Begon, M. 1982. Yeasts and Drosophila. In: Ashburner, M., Carson H.L., Thompson J. (Eds.), The genetics and biology of Drosophila, Academic Press, New York, pp 345384.

Bownes, M., Scott, A., Shirras, A., 1988. Dietary components modulate yolk protein gene transcription in Drosophila melanogaster. Development 103, 119-128.

Bradford, M.M. 1976., A rapid and sensitive method for the quantitation of microgram quantities of protein utilizing the principle of protein-dye binding. Anal. Biochem. 72, 248-254.

Burger, J.M.S., Hwangbo, D.S., Corby-Harris, V., Promislow, D.E.L., 2007. The functional costs and benefits of dietary restriction in Drosophila. Aging Cell 6, 63-71.

Carey, J.R., Harshman, L.G., Liedo, P., Müller, H.G., Wang, J.L., Zhang, Z., 2008. Longevity-fertility trade-offs in the tephritid fruit fly, Anastrepha ludens, across dietary restriction gradients. Aging Cell 7, 470-477.

Chen, C.P., Walker, V.K., 1994. Cold-shock and chilling tolerance in Drosophila. J. Insect Physiol. 40, 661- 669.

Chippindale, A.K., Leroi, A.M., Kim, S.B., Rose, M.R., 1993. Phenotypic plasticity and selection in Drosophila life history evolution. I. Nutrition and the cost of reproduction. J. Evol. Biol. 6, 171-193.

Chown, S.L., Nicolson, S.W., 2004. Insect Physiological Ecology: Mechanisms and Patterns, Oxford University Press, Oxford.

Colinet, H., Boivin, G., 2011. Insect parasitoids cold storage: A comprehensive review of factors of variability and consequences. Biol. Control 58, 83-95.

Colinet, H., Renault, D., 2012. Metabolic effects of $\mathrm{CO} 2$ anaesthesia in Drosophila melanogaster. Biol. Lett. 8, 1050-1054. 
Colinet, H., Hance, T., Vernon, P., 2006. Water relations, fat reserves, survival, and longevity of a cold-exposed parasitic wasp Aphidius colemani (Hymenoptera : Aphidiinae). Environ. Entomol. 35, 228-236.

Colinet, H., Larvor, V., Laparie, M., Renault, D., 2012a. Exploring the plastic response to cold acclimation through metabolomics. Funct. Ecol. 26, 711-722.

Colinet, H., Renault, D., Charoy-Guével, B., Com, E., 2012b. Metabolic and proteomic profiling of diapause in the aphid parasitoid Praon volucre. PLoS One 7, e32606.

Colinet, H., Larvor, V., Bical, R., Renault, D., 2013a. Dietary sugars affect cold tolerance of Drosophila melanogaster. Metabolomics. 9, 608-622.

Colinet, H., Siaussat, D., Bozzolan, F., Bowler, K., 2013b. Rapid decline of cold tolerance at young age is associated with expression of stress genes in Drosophila melanogaster. J. Exp. Biol. 216, 253-259.

Davis, G.R.F., 1975. Essential dietary amino acids for growth of larvae of the yellow mealworm, Tenebrio molitor L. J. Nutr. 105, 1071-1075.

Doucet, D., Walker, V.K., Qin, W., 2009. The bugs that came in from the cold: molecular adaptations to low temperatures in insects. Cell. Mol. Life Sci. 66, 1404-1418.

Ellers, J., Ruhe, B., Visser, B., 2011. Discriminating between energetic content and dietary composition as an explanation for dietary restriction effects. J. Insect Physiol. 57, 16701676.

Foray, V., Pelisson, P.F., Bel-Venner, M.C., Desouhant, E., Venner, S., Menu, F., Giron, D., Rey, B., 2012. A handbook for uncovering the complete energetic budget in insects: the van Handel's method (1985) revisited. Physiol. Entomol. 37, 295-302.

Ganter, P.F., 2006. Yeast and Invertebrate Associations. In: Rosa, C.A., Szabo P.G. (Eds.), Biodiversity and Ecophysiology of Yeasts, Springer, New York, pp 303-370.

Garrett, R.H., Grisham, C.M., 1999. Biochemistry. Second Edition, Saunders College Publishing, Fort Worth, TX.

Hallman, G.J., Denlinger, D.L., 1998. Temperature sensitivity in insects and applications in integrated pest management, Westview Press, USA.

Kostál, V., Šimek, P., Zahradníčková, H., Cimlová, J., Štětina, T., 2012. Conversion of the chill susceptible fruit fly larva (Drosophila melanogaster) to a freeze tolerant organism. Proc. Natl. Acad. Sci. USA 109, 3270-3274.

Lease, H., Wolf, B., 2011. Lipid content of terrestrial arthropods in relation to body size, phylogeny, ontogeny and sex. Physiol. Entomol. 36, 29-38. 
559

560

561

562

563

564

565

566

567

568

569

570

571

572

573

574

575

576

577

578

579

580

581

582

583

584

585

586

587

588

589

590

591

Le Bourg, E., 2010. Combined effects of suppressing live yeast and of a cold pretreatment on longevity, aging and resistance to several stresses in Drosophila melanogaster. Biogerontology 11, 245-254.

Le Bourg, E., Medioni, J., 1991. Food restriction and longevity in Drosophila melanogaster. Age Nutr. 2, 90-94.

Le Rohellec, M., Le Bourg, E., 2009. Contrasted effects of suppressing live yeast from food on longevity, aging and resistance to several stresses in Drosophila melanogaster. Exp. Gerontol. 44, 695-707.

Leroi, A.M., Chippindale, A.K., Rose, M.R., 1994. Long term evolution of a life history trade-off in Drosophila melanogaster. 1. The role of genotype by environment interaction. Evolution 48, 1244-1257.

Markow, T , O’Grady, P.M., 2006. Drosophila: A guide to species identification and use, Academic Press, London.

Markow, T.A., Raphael, B., Breitmeyer, C.M., Dobberfuhl, D., Elser, J.J., Pfeiler, E., 1999. Elemental stoichiometry of Drosophila and their hosts. Funct. Ecol. 13, 78-84.

Min, K.J., Tatar, M. 2006. Drosophila diet restriction in practice: Do flies consume fewer nutrients? Mech. Ageing Dev. 127, 93-96.

Moore, P.J., Attisano, A., 2011. Oosorption in response to poor food: complexity in the tradeoff between reproduction and survival. Ecol. Evol. 1, 37-45.

Musselman, L.P., Fink, J.L., Narzinski, K., Ramachandran, P.V., Hathiramani, S.S., Cagan, R.L., Baranski, T.J., 2011. A high-sugar diet produces obesity and insulin resistance in wild-type Drosophila. Dis. Model Mech. 4, 842-849.

Nyamukondiwa, C., Terblanche, J.S., 2009. Thermal tolerance in adult Mediterranean and Natal fruit flies (Ceratitis capitata and Ceratitis rosa): Effects of age, gender and feeding status. J. Therm. Biol. 34, 406-414.

Overgaard, J., Malmendal, A., Sørensen, J.G., Bundy, J.G., Loeschcke, V., Nielsen, N.C., Holmstrup, M., 2007. Metabolomic profiling of rapid cold hardening and cold shock in Drosophila melanogaster. J. Insect Physiol. 53, 1218-1232.

Packard, G.C., Boardman, T.J., 1999. The use of percentages and size-specific indices to normalize physiological data for variation in body size: wasted time, wasted effort? Comp. Biochem. Physiol. A 122, 37-44.

Parsons, P.A., 1991. Evolutionary rates: Stress and species boundaries. Annu. Rev. Ecol. Syst. $22,1-18$. 
Partridge, L., Piper, M.D.W., Mair, W., 2005. Dietary restriction in Drosophila. Mech. Ageing Dev. 126, 938-950.

R Development Core Team., 2008. R: a language and environment for statistical computing. $\mathrm{R}$ Foundation for Statistical Computing, Vienna, ISBN 3-900051-07-0, $<\mathrm{http}: / / \mathrm{www}$. Rproject.org $>$.

Rako, L., Hoffmann, A.A., 2006. Complexity of the cold acclimation response in Drosophila melanogaster. J. Insect Physiol. 52, 94-104.

Sang, J.H., King, R., 1961. Nutritional requirements of axenically cultured Drosophila melanogaster adults. J. Exp. Biol. 38, 793-809.

Simmons, F.H., Bradley, T.J., 1997. An analysis of resource allocation in response to dietary yeast in Drosophila melanogaster. J. Insect Physiol. 43, 779-788.

Sisodia, S., Singh, B.N.,2012. Experimental evidence for nutrition regulated stress resistance in Drosophila ananassae. PLoS One 7, e46131.

Skorupa, D.A., Dervisefendic, A., Zwiener, J., Pletcher, S.D., 2008. Dietary composition specifies consumption, obesity, and lifespan in Drosophila melanogaster. Aging Cell 7, 478-490.

Starmer, W., Fogleman, J., 1986. Coadaptation of Drosophila and yeasts in their natural habitat. J. Chem. Ecol. 12, 1037-1055.

Stocker, H., Gallant, P., 2008. Getting started: an overview on raising and handling Drosophila. Methods Mol. Biol. 420, 27-44.

Storey, K.B., 1983. Metabolism and bound water in overwintering insects. Cryobiology 20, 365-379.

Storey, K.B., Storey, J.M., 2012. Insect cold hardiness: metabolic, gene, and protein adaptation. Can. J. Zool. 90, 456-475.

Teets, N., Denlinger, D. 2013. Physiological mechanisms of seasonal and rapid coldhardening in insects. Physiol. Entomol. 38, 115-116.

Wang, L., Clark, A.G., 1995. Physiological genetics of the response to a high-sucrose diet by Drosophila melanogaster. Biochem. Genet. 33, 149-165.

Williams, C.M., Thomas, R.H., MacMillan, H.A., Marshall, K.E., Sinclair, B.J., 2011. Triacylglyceride measurement in small quantities of homogenised insect tissue: comparisons and caveats. J. Insect Physiol. 57: 1602-13

Wolfe, G.R., Hendrix, D.L., Salvucci, M.E., 1998. A thermoprotective role for sorbitol in the silverleaf whitefly, Bemisia argentifolii. J. Insect Physiol. 44, 597-603. 
625 Xia, J., Wishart, D.S. 2010. MetPA: a web-based metabolomics tool for pathway analysis and 626 visualization. Bioinformatics 26, 2342-2344.

627

628

629

630

631

632

633

634

635

636

637

638

639

640

641

642

643

644

645

646

647 
Table 1: List of metabolites detected in females of Drosophila melanogaster

Compounds abbreviations in brackets

Free amino acids

Alanine (Ala)

Valine (Val)

Serine (Ser)

Leucine (Leu)

Threonine (Thr)

Proline (Pro)

Methionine (Met)

Ornithine (Orn)

Glycine (Gly)

Isoleucine (Ile)

Glutamate (Glu)

Lysine (Lys)

Phenylalanine (Phe)

Tyrosine (Tyr)

Sugars
Polyols

Sorbitol

Glycerol

Glycerol-3-Phosphate

Inositol

Xylitol

Intermediate metabolites

Succinate

Malate

Citrate

Fumarate

Other metabolites

Lactate

Ethanolamine (ETA)

Free phosphate (PO4)

Gamma-aminobutyric acid (GABA)

Glucono delta-lactone (GDL)

Spermine
Sucrose (Suc)

Fructose (Fru)

Glucose (Glc)

Trehalose (Tre)

Mannose (Man)

Galactose (Gal)

Ribose (Rib)

Maltose (Mal)

Glucose-6-phosphate (G6P) 
652 Figure 1: Schematic diagram of the experimental design used to investigate the effect of

653

654

655

656

657

658

659

660

661

662

\section{(a)} dietary live yeast supplementation on mass parameters, cold tolerance and GC-MS metabolic profiles of D. melanogaster. In all experiments, the flies developed from egg to adult on a standard diet $[\mathrm{SAY}(-)]$. Emerging females were then fed on different diets for 6 days: SA $v s$. $\mathrm{SAY}(+)$ for experiment 1 and $\mathrm{SAY}(-)$ vs. $\mathrm{SAY}( \pm)$ for experiment 2. In the experiment 3 , females were fed on the same experimental conditions as in experiment 2, but they were starved for $8 \mathrm{~h}$ before sampling, St-SAY(-) vs. St-SAY( \pm ). Symbols S, A and Y for sugar, agar and yeast, respectively. Sign (+), (-) and ( \pm ) for live yeast only, killed yeast only, and both live and killed yeast, respectively.

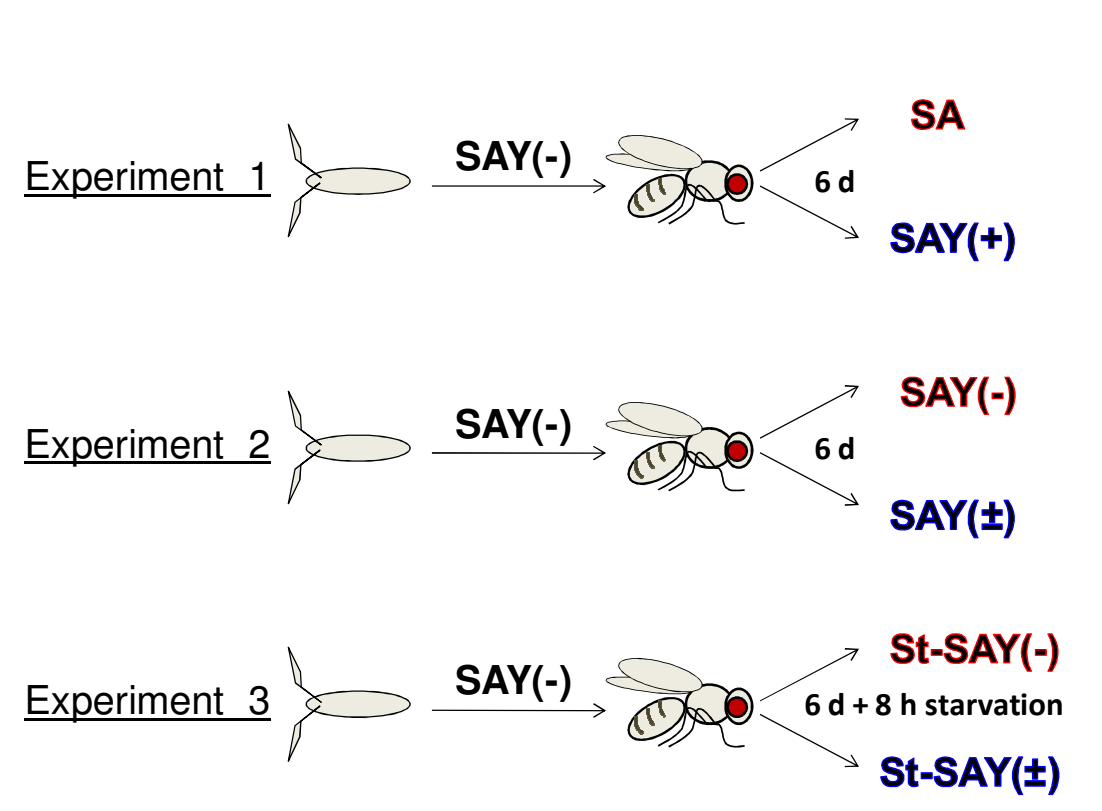

\begin{tabular}{|c|c|c|}
\hline Mass & Cold test & GC-MS \\
\hline $\mathrm{X}$ & $\mathrm{X}$ & $\mathrm{X}$ \\
\hline $\mathrm{X}$ & $\mathrm{X}$ & $\mathrm{X}$ \\
\hline $\mathrm{X}$ & $\mathrm{X}$ & $\mathrm{X}$ \\
\hline & & $\mathrm{X}$ \\
\hline & & $\mathrm{X}$ \\
\hline
\end{tabular}

663

664

665

666

667

668

669

670

671

672

673 
674 Figure 2: (A) Body mass parameters showing changes in lipid mass (LM), lean dry mass 675 (LDM), and water mass (WM) according to nutritional treatment [SA, SAY(+), SAY(-), $676 \mathrm{SAY}( \pm)](n=15)$. (B) Total protein content of female D. melanogaster $(n=12)$.
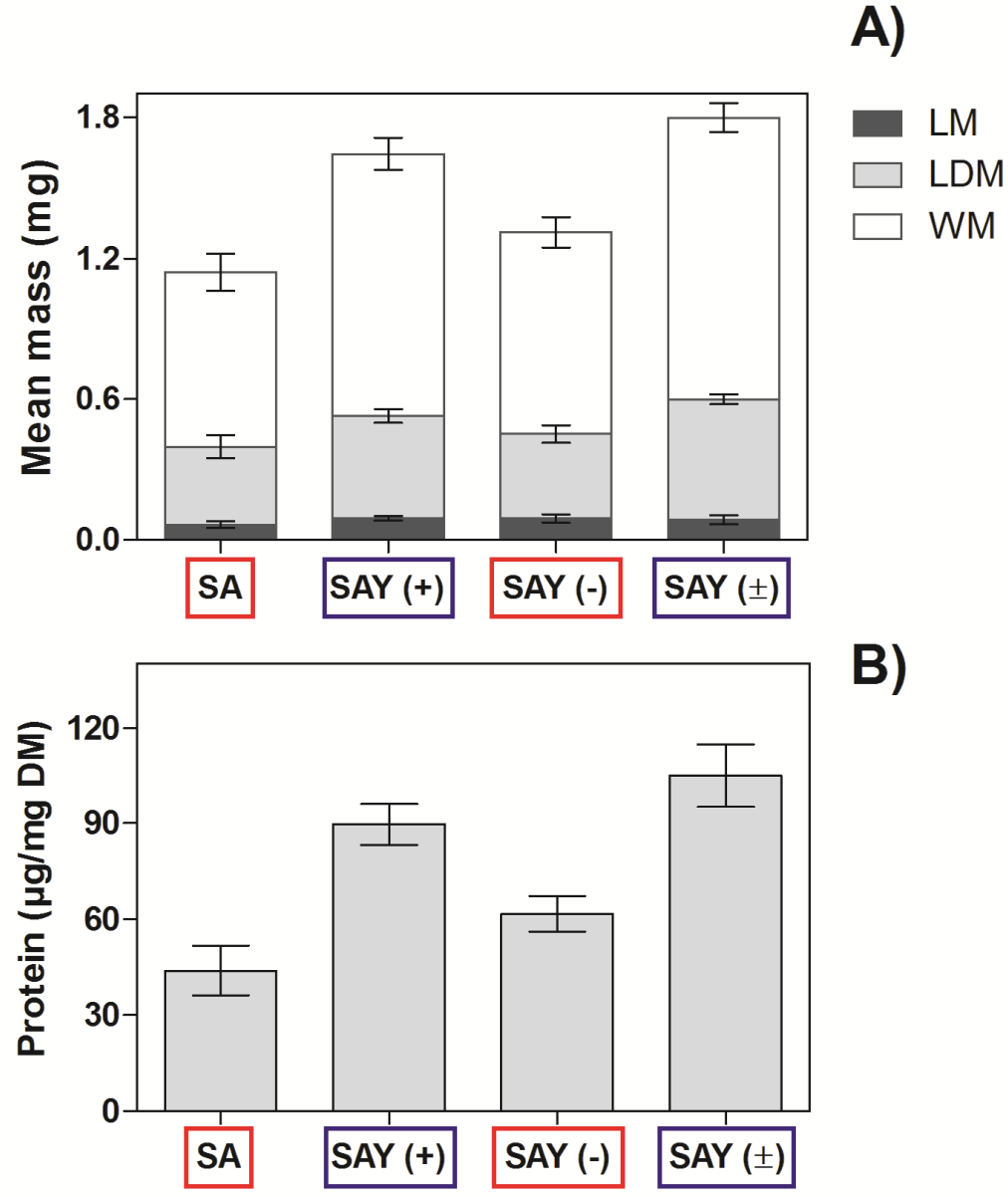

B)

677

678

679

680

681

682

683

684

685

686

687

688

689 
Figure 3: Composite panel summarizing all the cold tolerance assays of the experiment 1 . Temporal recovery curves of live yeast-fed females [blue line, SAY(+)] and yeast-deprived females [red line, SA] exposed to chronic cold stress $\left(0{ }^{\circ} \mathrm{C}\right)$ for various durations: 8,10 and $12 \mathrm{~h}$ in figures $\mathrm{A}, \mathrm{D}$, and $\mathrm{G}$, respectively. Each line represents the mean proportion $( \pm 95 \%$ confidence interval) of recovering flies in relation to time after cold stress $(n=50)$. Mortality rates, assessed $24 \mathrm{~h}$ after the chronic cold stresses, are shown in figures $\mathrm{B}, \mathrm{E}$ and $\mathrm{H}$ for each nutritional treatment [SA $v s$. SAY $(+)](n=50)$. Mortality rates assessed $24 \mathrm{~h}$ after an acute cold stress $\left(-3.5^{\circ} \mathrm{C}\right)$ for various durations: $90,120,135 \mathrm{~min}$ are shown in figures $\mathrm{C}, \mathrm{F}$ and $\mathrm{I}$, respectively $(n=100)$. The black part of the bars represents the percent mortality and grey part is percent survival.

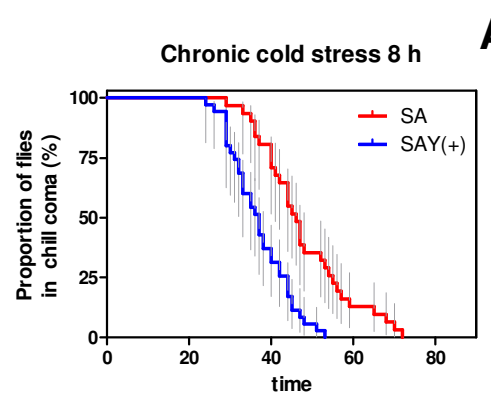

A)

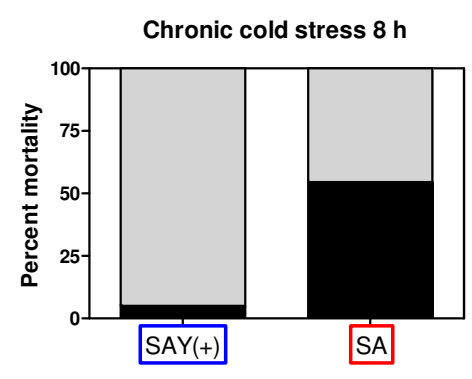

D)
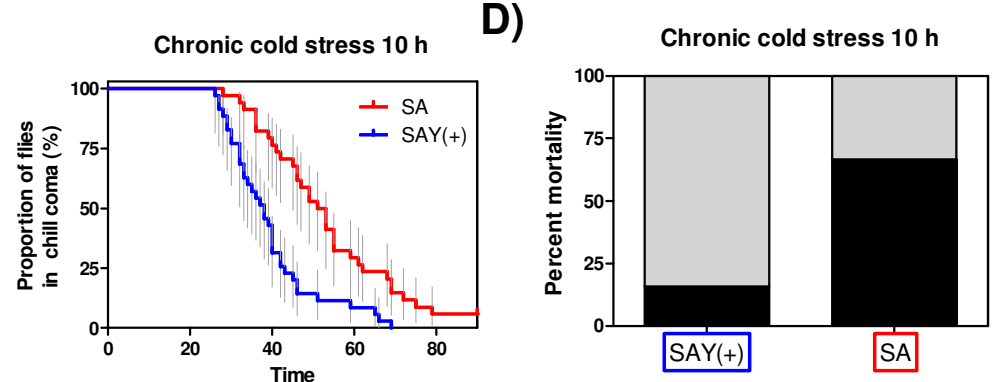

G)
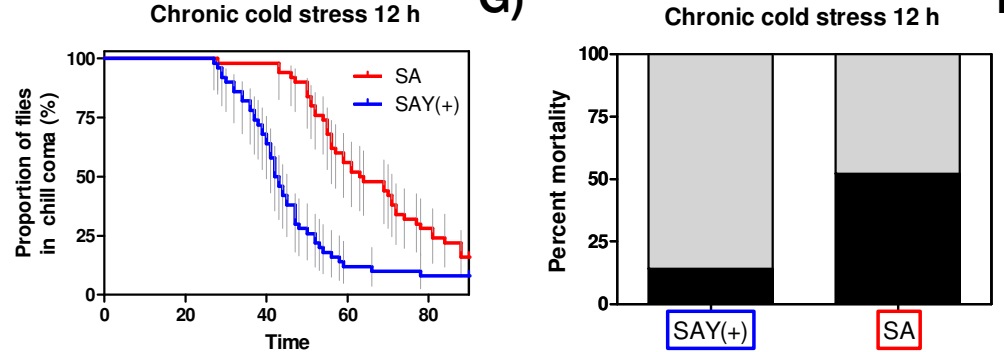

B)

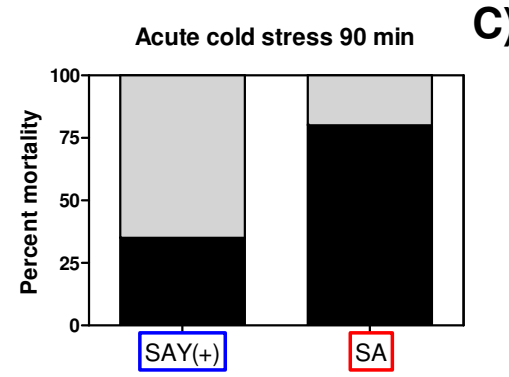

E)

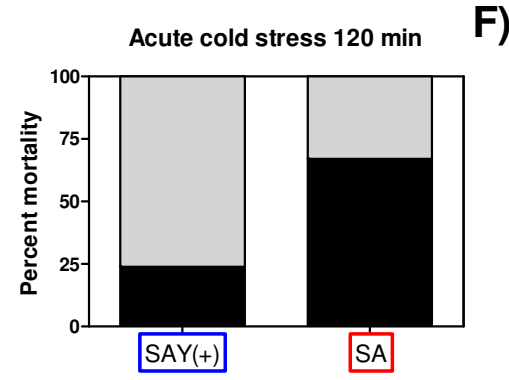

H)

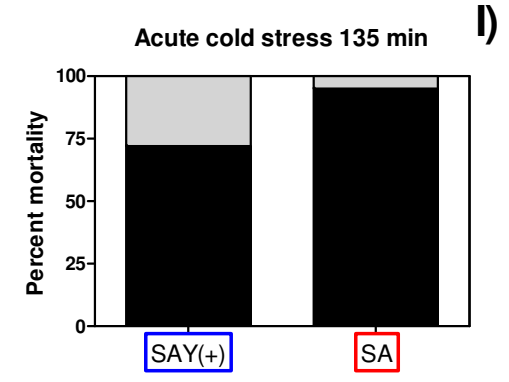

F) 
Figure 4: Composite panel summarizing the cold tolerance assays of the experiment 2. Temporal recovery curves of live yeast-fed females [blue line, SAY $( \pm)$ ] and live yeastdeprived females [red line, SAY(-)] exposed to chronic cold stress $\left(0{ }^{\circ} \mathrm{C}\right)$ for various durations: 10 and $12 \mathrm{~h}$ in figures $\mathrm{A}$ and $\mathrm{D}$, respectively. Each line represents the mean proportion ( $\pm 95 \%$ confidence interval) of recovering flies in relation to time after cold stress $(n=50)$. Mortality rates, assessed $24 \mathrm{~h}$ after the chronic cold stresses, are shown in figures $\mathrm{B}$, and $\mathrm{E}$ for each nutritional treatment [SAY(-) vs. SAY $( \pm)](n=50)$. Mortality rates assessed 24 $\mathrm{h}$ after an acute cold stress $\left(-3.5^{\circ} \mathrm{C}\right)$ for various durations: 90 and $120 \mathrm{~min}$ are shown in

714 figures $\mathrm{C}$ and $\mathrm{F}$, respectively $(n=100)$. The black part of the bars represents the percent mortality and the grey part is percent survival.

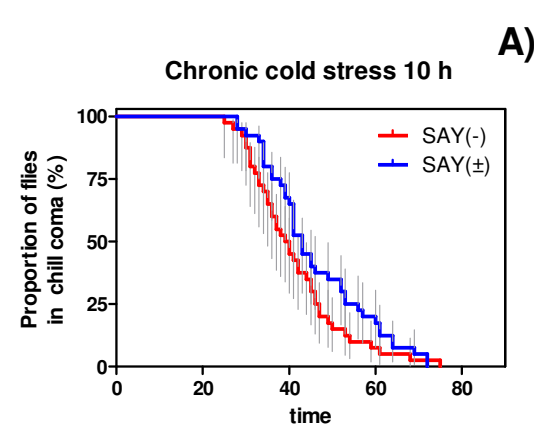

A)

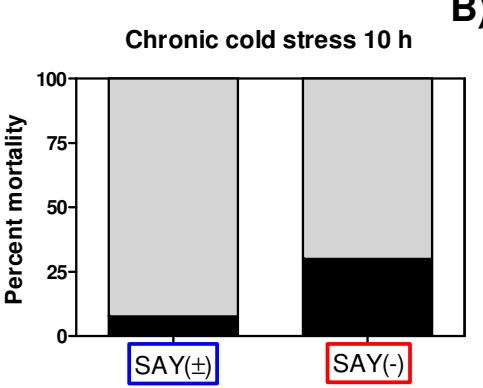

B)
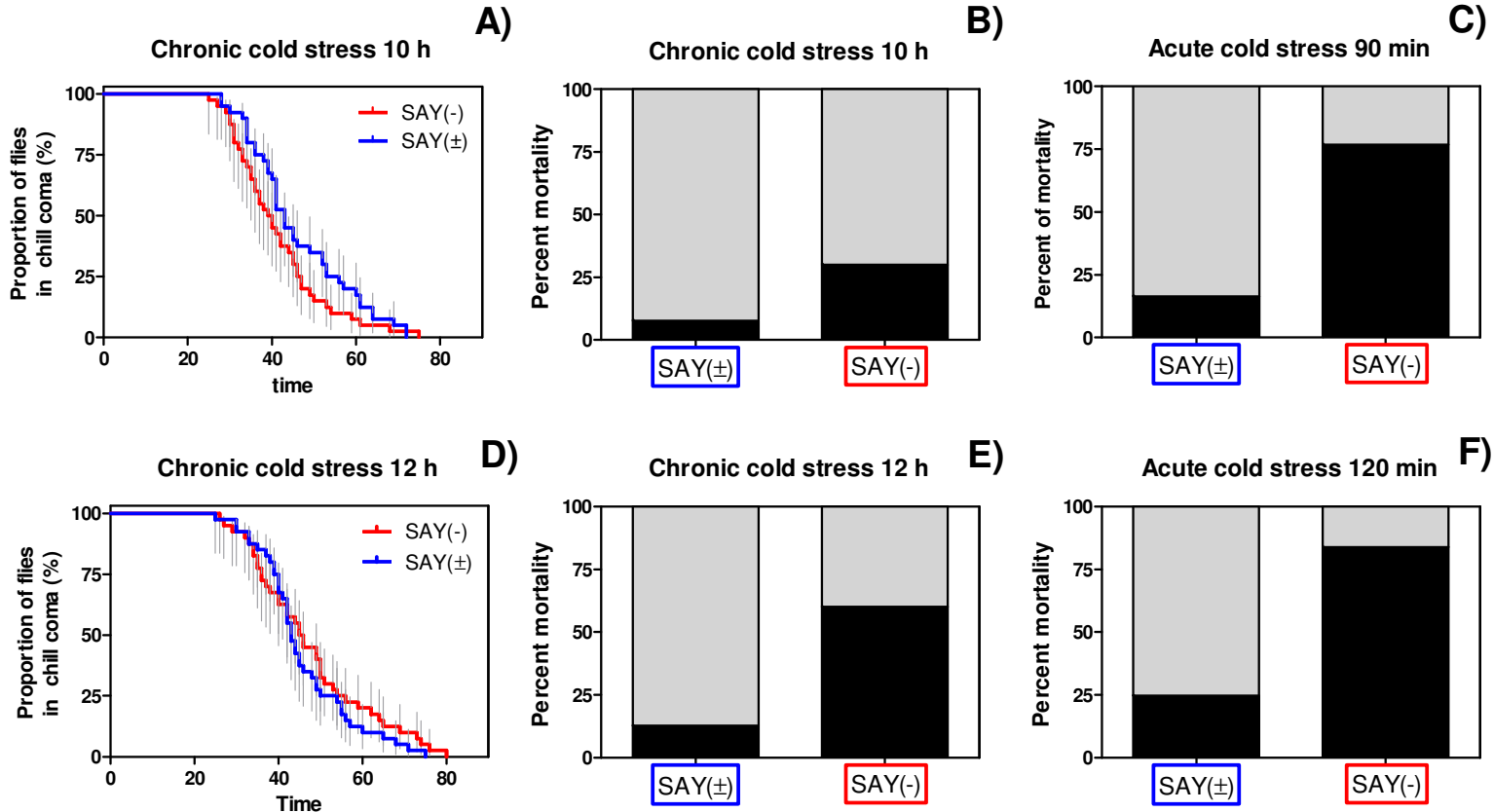

D)

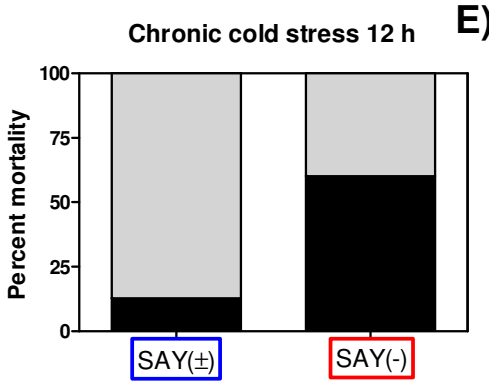

E)

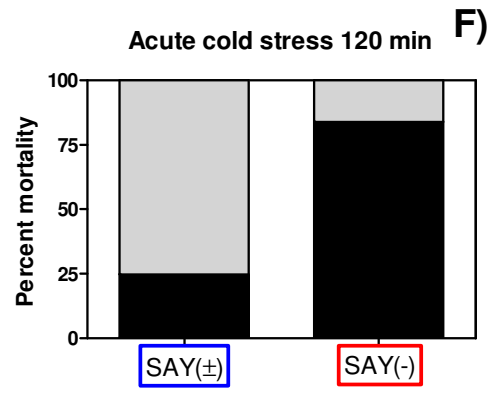

716 
723 Figure 5: (A) Multivariate analysis (PCA) based on the GC/MS metabolomic data of the 724 experiment 1 illustrating the plotting of PC1 against PC2. The unit "d" (top right of the plot) represents the side-length of a square in the grid. A clear separation was observed between 726 live yeast-fed [blue ellipse, SAY $(+)$ ] and yeast-deprived metabotypes [red ellipse, SA]. Lines 727 link replicates to their respective centroids $(n=6)$. (B) Correlation values of the different 728 metabolite concentrations to the principal components $\mathrm{PC} 1$ in the principal component 729 analysis. Correlations are ranked on Y-axis according to their values. Blue bars for negative 730 correlations (i.e. accumulated in $\mathrm{SAY}(+)$ flies) and red bars for positive correlations (i.e. accumulated in SA flies). See Dataset S1 for detailed concentrations and fold changes.

A)

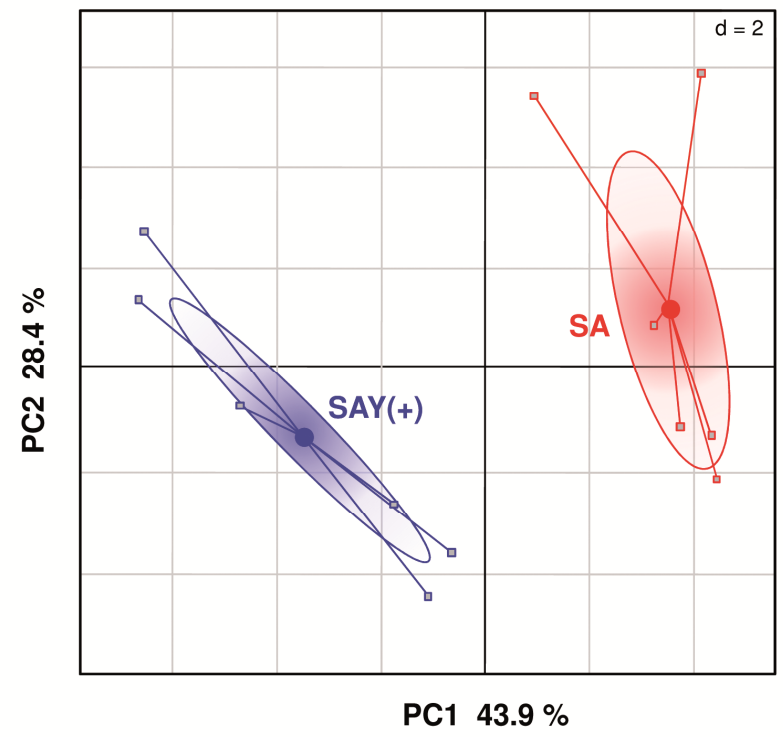

B)

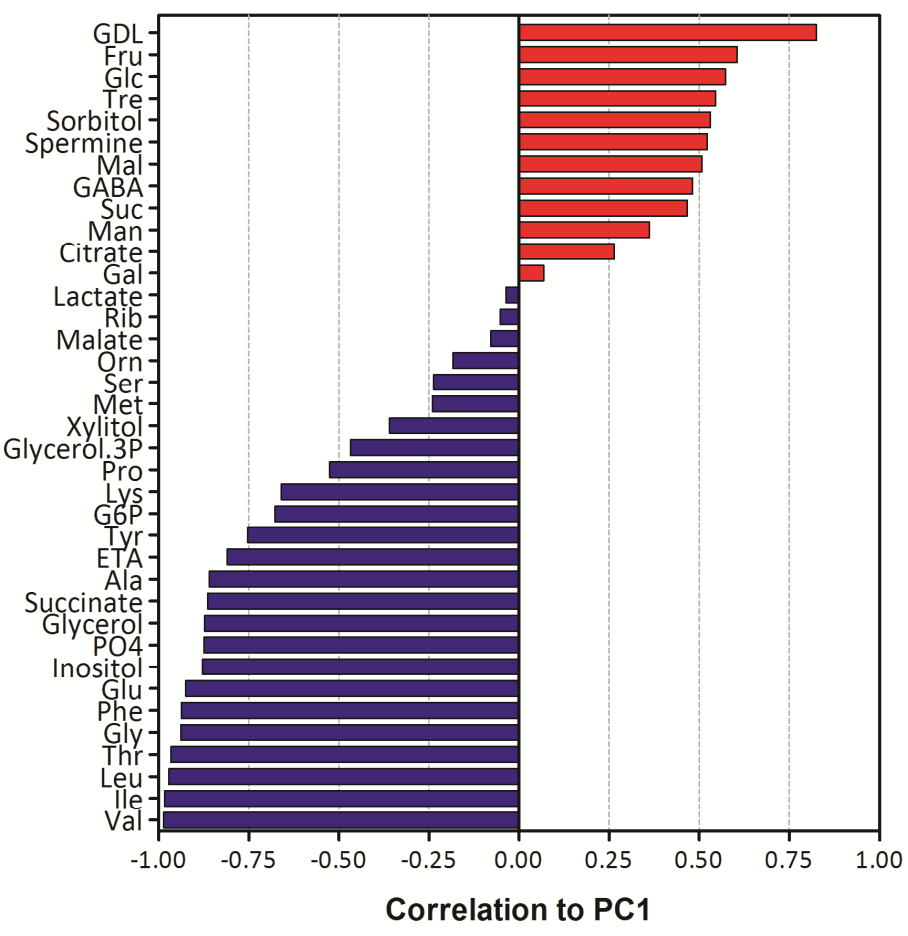


Figure 6: (A) Multivariate analysis (PCA) based on the GC/MS metabolomic data of the experiment 2 illustrating the plotting of PC1 against PC2. The unit "d" (top right of the plot) represents the side-length of a square in the grid. A clear separation was observed between live yeast-fed [blue ellipse, $\mathrm{SAY}( \pm)$ ] and live yeast-deprived metabotypes [red ellipse, SAY(-)]. Lines link replicates to their respective centroids $(n=6)$. (B) Correlation values of the different metabolite concentrations to the principal components PC1 in the principal component analysis. Correlations are ranked on $\mathrm{Y}$-axis according to their values. Blue bars for negative correlations (i.e. accumulated in $\mathrm{SAY}( \pm)$ flies) and red bars for positive correlations (i.e. accumulated in SAY(-) flies). See Dataset S2 for detailed concentrations and fold changes.

B)

A)

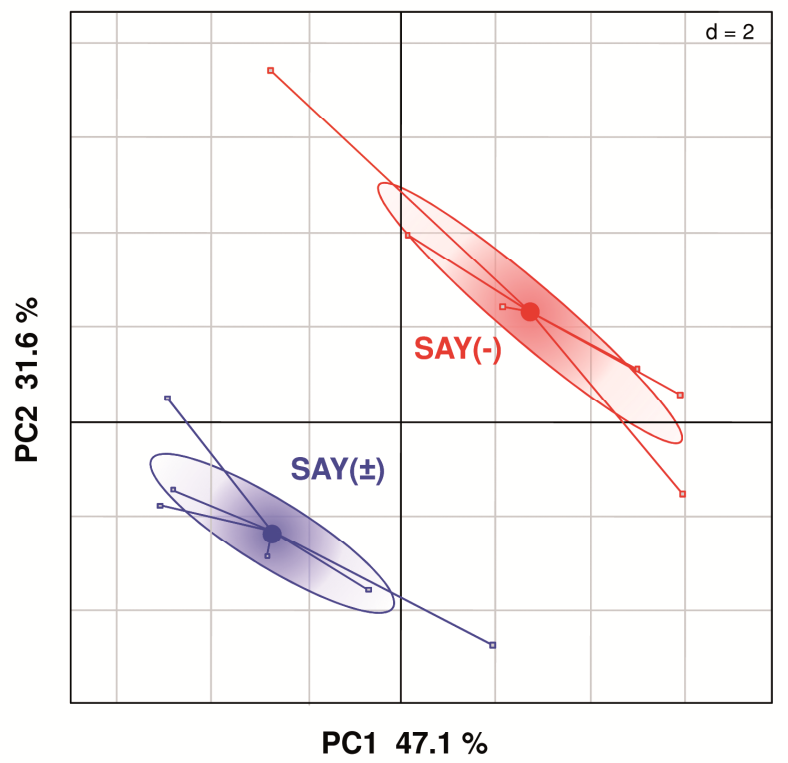

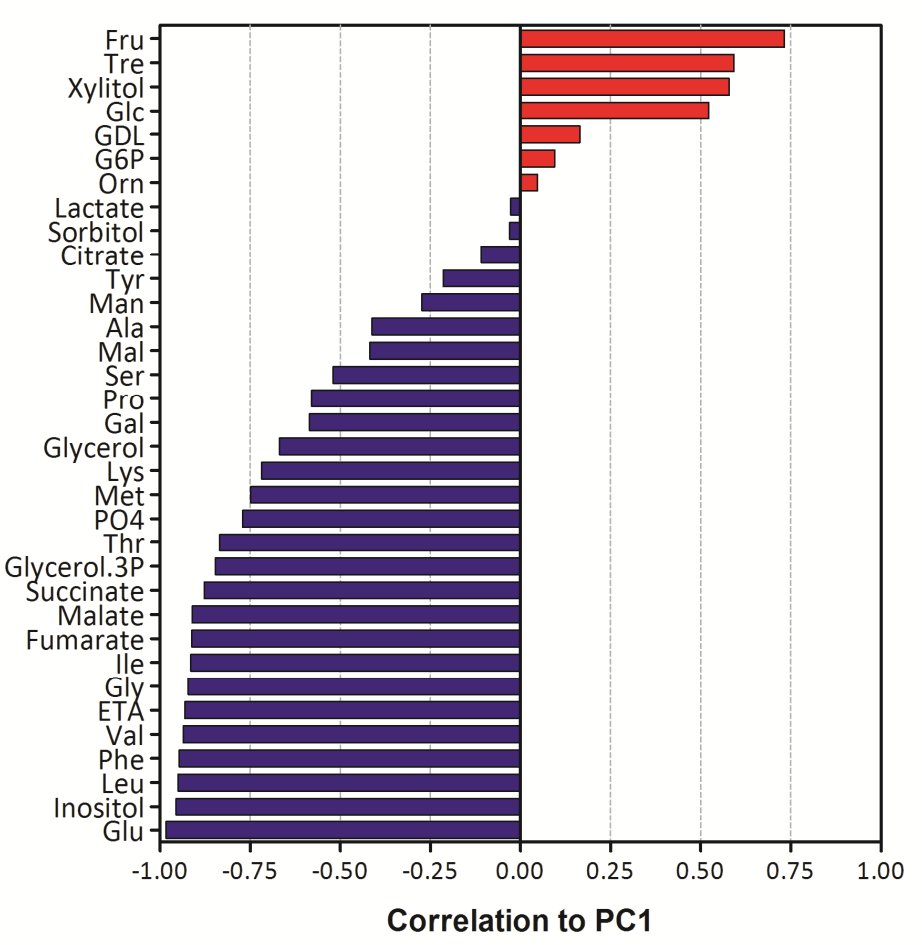


757 Figure 7: (A) Multivariate analysis (PCA) based on the GC/MS metabolomic data of the experiment 3 illustrating the plotting of PC1 against PC2. The unit "d" (top right of the plot) represents the side-length of a square in the grid. A clear separation was observed between live yeast-fed [blue ellipse, St-SAY $( \pm)$ ] and live yeast-deprived metabotypes [red ellipse, StSAY(-)]. Lines link replicates to their respective centroids $(n=6)$. (B) Correlation values of the different metabolite concentrations to the principal components PC1 in the principal component analysis. Correlations are ranked on Y-axis according to their values. Blue bars for negative correlations (i.e. accumulated in $\mathrm{St}-\mathrm{SAY}( \pm)$ flies) and red bars for positive correlations (i.e. accumulated in St-SAY(-) flies). See Dataset S3 for detailed concentrations and fold changes.

B)

A)

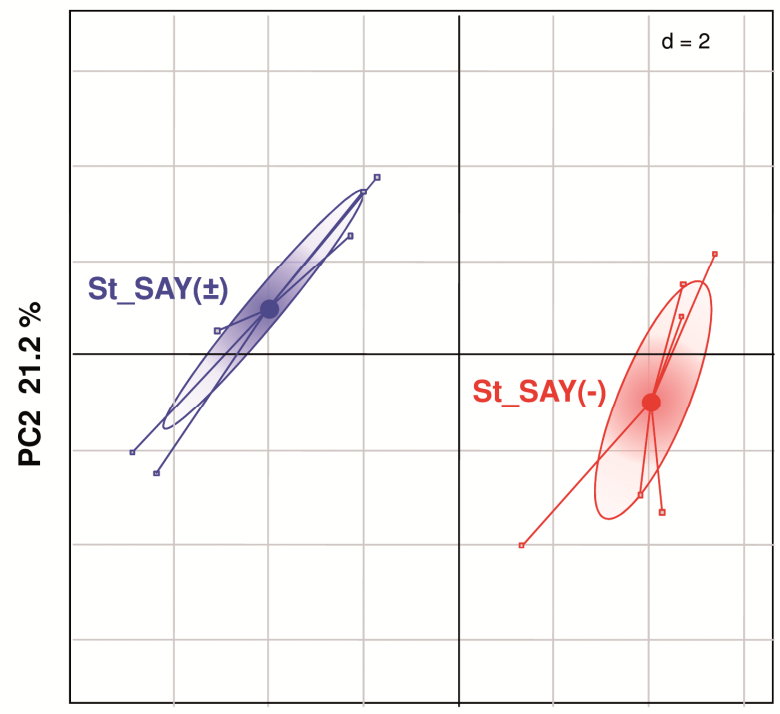

PC1 $57.3 \%$

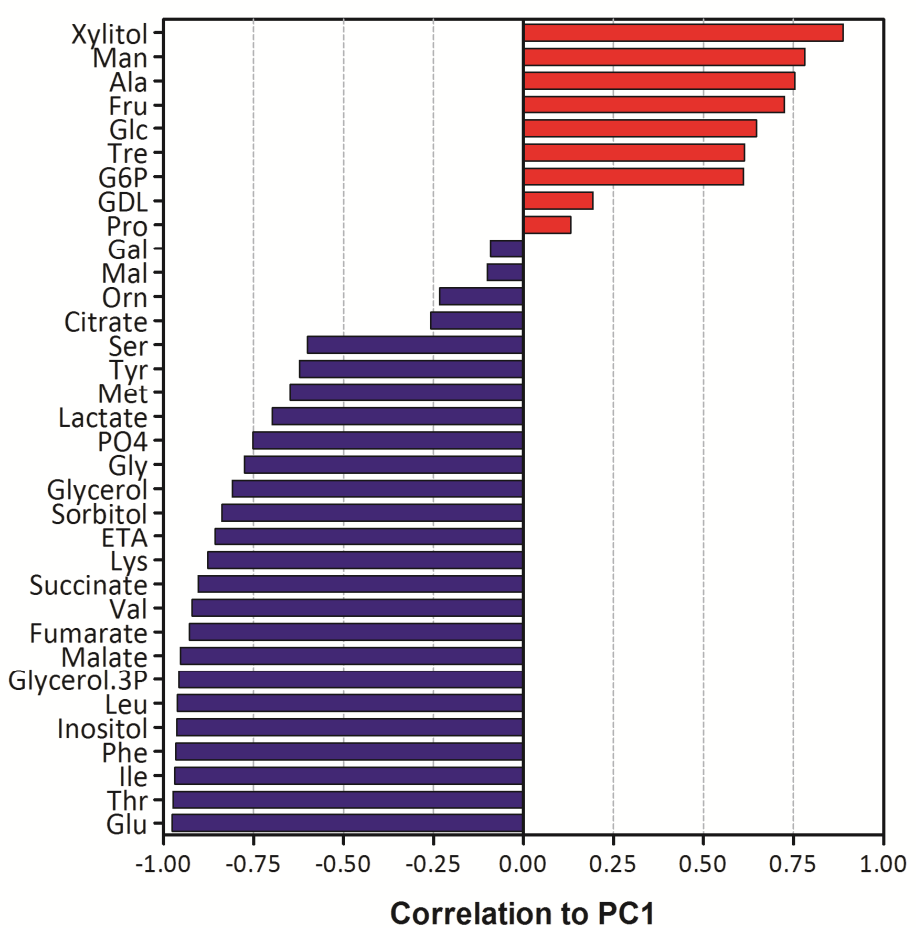

